\title{
HOW DOES IT INTEGRATION CAPACITY LESSEN WORK-FROM-HOME STRESSORS AND ANXIETY?
}

\author{
Linwu Gu, Indiana University of Pennsylvania, lqu@iup.edu \\ Jianfeng Wang, Indiana University of Pennsylvania, jwang@iup.edu
}

\begin{abstract}
Task technology fit model provides useful framework analyzing variables affecting work from home. However, few previous studies have extensively explored the relationship between work stressors, social interaction anxiety, and task technology fit. Data of 91 work from home subjects using an online questionnaire was collected and analyzed. The results show that the perceived IT integration capacity mitigates the negative effects of the work stressors and social interaction anxiety on task technology fit.
\end{abstract}

Keywords: Task Technology Fit, Work from Home Stressors, Perceived Social Interaction Anxiety, IT Integration Capacity

\section{INTRODUCTION}

More and more businesses have allowed their employees work from home to reduce the effects of the coronavirus pandemic. Businesses are facing challenges of how to maintain the productivity and performance of their employees when they work from home. However, technologies supporting work from home are expected to not only provide a direct communication channel, regularly check in with the team and managers but also provide an integrated and consistent access to all relevant information. With work from home, it can lead to something called work from home stressors negatively related to the task technology fit (Lu et al., 2014). People work from home who perceive social interaction anxiety are likely to feel uncomfortable to communicate with other team members, customers, and suppliers. To alleviate work from home problems, organization must enable IT collaboration capacity to support virtual coordination and discussion among all the users (Bala et al., 2017).

The perceived IT integration capability essentially integrates all needed business activities, information, and data (Benitez \& Walczuch, 2012; Rai \& Tang, 2010). Benitez \& Walczuch (2012) explore how IT capability can provide support for creative innovation. They find that IT capability is an enabler of proactive environmental strategy, which plays a significant role in mediating the effects of IT on firm performance. Rai \& Tang (2010) investigate how IT integration capability can support interorganizational relationship, which is strategically important to a business future and competitive advantage. In this paper, we study the negative effects of work from home stressors and social interaction anxiety on the task technology fit. Specifically, this work proposes that a moderator, the perceived IT integration capacity, can alleviate the impacts from stressors and anxiety related to work from home. This work sheds light on the supportive impacts of IT integration capability on the relationships among work stressors, social interaction anxiety, and task technology fit.

The remainder of the paper is structured as follows. First, we review the relevant theoretical work on task technology fit and develop a research model of moderation of IT integration capability on the relationships between work from home stressors and social interaction anxiety and task technology fit. The hypotheses and research design are then explained, followed by data analysis and discussion of the findings from our studies. We discuss the theoretical and practical implications of the findings at the end.

\section{THEORETICAL FOUNDATION AND RESEARCH MODEL}

Goodhue \& Thompson (1995) propose a technology-to-performance model, asserting that, for an information technology to have a positive influence on individual performance, the technology must be utilized, and there should be a good fit between the technology and the tasks it supports. Task technology fit theory explains how technology 
impacts individual performance and how individual characteristics and technological characteristics impact task technology fit and individual performance (Goodhue \& Thompson, 1995).

Past studies provide evidence of positive links between fit, user working environment to technology, and implementation (Parks, 2013; Zhou et al., 2010). Some research results indicate the need for a closer examination of the technology effects on the relationship between negative factors and task technology fit (Lu et al., 2014; Gu \&Wang, 2009).

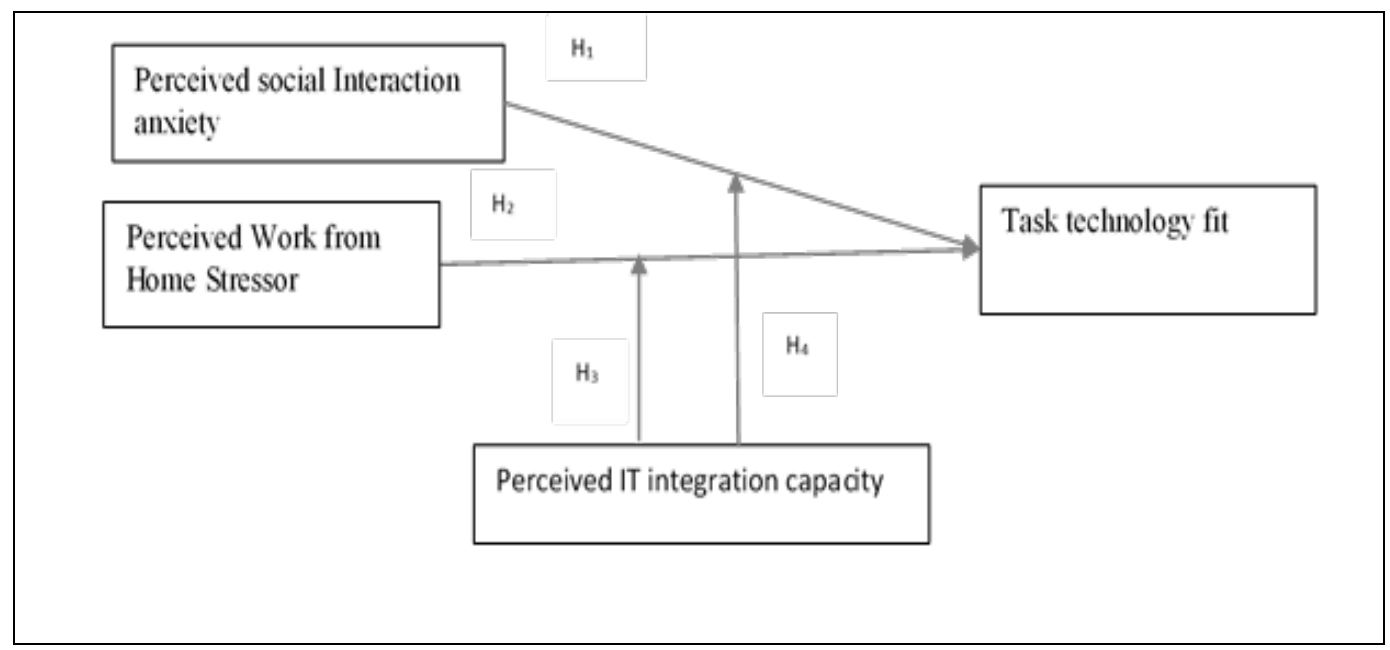

Figure 1. Research Model

\section{Perceived Integration Capacity}

IT integration capacity is likely one of the most important technology capacities, allowing the organization to integrate online and offline activities and combine external and internal resources to help work from home productivity (Pinjani \& Palvia, 2013). Moreover, IT integration capacity enables employees considering multiple sources of information together, e.g., images, orders, descriptions, and reviews, meaning that they take a multi-view perspective (Guan et al., 2019). IT integration capacity integrate various other resources to access to the most basic applications through remote desktops. Therefore, the IT integration capabilities incorporate business activities and information, thus emphasizing the enabling role of IT in creating business value (Benitez \& Walczuch, 2012; Rai \&Tang, 2010).

\section{Perceived Social Interaction Anxiety}

Work from home social interaction is also important for mental health and can help with work from home productivity. However, anxious individuals often avoid social interactions when work from home. The central concerns of social interaction anxiety include fears of being ignored, boring, and not knowing how to respond to others. Hence, social interactions anxiety appears to influence task technology unfitness, and leads a negative outcome (McCord \& Rodebaugh, 2014; Rachman et al., 2008). But appropriate technology adoption may alleviate social interaction anxiety (Lu \& Yang, 2014).

\section{Perceived Work from Home Stressors}

Work from home stressors have been defined as stressful demands beyond manageable by employees and might obstruct the perception of task technology fit (Wallace et al., 2009). Specifically, when work from home stressors are perceived unmanageable, they would induce negative reactions such as anger, fear, and frustration of using technology. And work-stressed employees would encounter difficulty in exerting any effort on productivity (Guan et al., 2019). However, previous studies found that perceived IT integration capacity minimizes social interaction anxiety in the mobile social community context (Yang et al., 2016). Specifically, when stressors are perceived unmanageable, they would induce negative reactions such as anger, fear, and frustration among employees (Firth et al., 2019). IT 
integration capacity may enable stressed employees to integrate data and activities for their work, thereby reducing the negative effect of work stressors on task technology fit (Ding et al., 2019).

In this study, the construct of perceived task technology fit is defined as the perception of the degree to which the IT integration capability provided by work from home systems can support their work or coursework. The integrated IT platforms can virtually connect people across organizations. Empirical evidence supports the negative effects of interaction anxiety on task technology fit. The IT integration capacity alleviate social interaction anxiety, when people across organizations share knowledge, interpretation, and analysis of data (Liu et al., 2016). Furthermore, some scholars indicate that employees could perceive certain work stressors that could be reduced by IT capability (Braojos et al., 2020).

Therefore, we propose the following hypotheses:

$\mathrm{H}_{1}$ : Perceived work from home stressors negatively influence perceived task technology fit.

$\mathrm{H}_{2}$ : Perceived social interaction anxiety negatively influences perceived task technology fit.

$\mathrm{H}_{3}$ : Perceived IT integration capacity positively moderates the relationship between perceived work from home stressors and perceived task technology fit.

$\mathrm{H}_{4}$ : Perceived IT integration capacity positively moderates the relationship between perceived social interaction anxiety and perceived task technology fit.

\section{RESEARCH METHODOLOGY}

\section{Subjects and Procedures}

Data was collected from 91 subjects who worked from home during quarantine period. First, we designed the survey questionnaires on the shared google word documents, and posted the links on our social media accounts, and we introduced our research topic, the survey, through Facebook link, our WeChat moments and WeChat groups we participate. At the end, all subjects providing data are either from our WeChat connections or WeChat groups. Most of them work in IT industry (33), financial service industry (27), and higher education or consulting industry (22), and about 9 in other industries.

Table 1. Sample Demographic

\begin{tabular}{|l|l|}
\hline Gender & $\begin{array}{l}\text { Male: 62 } \\
\text { Female: } 29\end{array}$ \\
\hline Age & $30-39:$ 67 \\
& $40-49: 21$ \\
& 50-60: 3 \\
\hline Education & Bachelor: 56 \\
& Master/PhD: 35 \\
\hline Industry & IT: 33 \\
& Financial service: 27 \\
& Higher education/Consulting: 22 \\
& Other: 9 \\
\hline
\end{tabular}

\section{Measurement}


Measurement scales were taken from the literature and adapted to this research context. All scale items were derived from the existing literature. All the scales were assessed with seven-point Likert scales with anchor points of 1= "totally disagree" and 7= "totally agree." (For a detailed description of measurement items, please refer to the appendix).

\section{Confirmatory Factor Analysis}

Reliability and validity of the reflective constructs were evaluated by testing their internal reliability, convergent validity, and discriminant validity. We calculated the values of composite reliability, average variance extracted, to assess the internal reliability and convergent validity. As shown in Tables 2 and 3, all indicators are above the threshold value of 0.7 , thus demonstrating that all reflective constructs exhibiting good reliability and convergent validity.

Table 2. Internal Consistency of Model Constructs

\begin{tabular}{|l|l|l|l|}
\hline Construct items & $\begin{array}{l}\text { Composite } \\
\text { reliability }\end{array}$ & AVE & AVE square root \\
\hline PSIA & 0.82 & 0.83 & 0.91 \\
\hline PWHS & 0.87 & 0.71 & 0.84 \\
\hline PITIC & 0.76 & 0.79 & 0.89 \\
\hline PTTF & 0.81 & 0.73 & 0.85 \\
\hline $\begin{array}{l}\text { Variables: Perceived social interaction anxiety (PSIA), Perceived work from } \\
\text { home stressors (PWHS), Perceived IT integration capacity (PITIC), Perceived } \\
\text { task technology fit (PTTF). }\end{array}$ \\
\hline
\end{tabular}

Table 3. Square Root of AVE and Cross-Correlations

\begin{tabular}{|c|c|c|c|c|}
\hline & PSI & PNA & PTP & PS \\
\hline $\begin{array}{l}\text { PSIA } \\
\end{array}$ & 0.912 & & & \\
\hline PWHS & 0.647 & 0.843 & & \\
\hline PITIC & 0.535 & 0.625 & 0.889 & \\
\hline PTTF & 0.321 & 0.236 & 0.635 & 0.854 \\
\hline \multicolumn{5}{|c|}{$\begin{array}{l}\text { Variables: Perceived social interaction anxiety (PSIA), Perceived work from home } \\
\text { stressors (PWHS), Perceived IT integration capacity (PITIC), Perceived task } \\
\text { technology fit (PTTF). }\end{array}$} \\
\hline
\end{tabular}

\section{ANALYSIS AND RESEARCH FINDINGS}

\section{Main Effect Results}

We employed structural equation modeling (SEM) technique to validate the research model. The findings of the structural equation modeling (Table 4) that work from home stressors have a negative effect on task technology fit ( $\beta=-0.352, p<0.001$ ) and social interaction anxiety also has a negative effect on task technology $(~ \beta=-0.260, p<0.001)$. 
Table 4. Results of SEM

\begin{tabular}{|c|l|l|l|l|}
\hline Hypothesis & Relationship & $\begin{array}{l}\text { Beta } \\
\text { coefficient }\end{array}$ & t-value & $\begin{array}{l}\text { Hypothesis } \\
\text { supported }\end{array}$ \\
\hline $\mathrm{H}_{1}(-)$ & $\begin{array}{l}\text { work from home stressors ->perceived } \\
\text { task technology fit }\end{array}$ & -0.352 & $4.705^{* * *}$ & Yes \\
\hline $\mathrm{H}_{2}(-)$ & $\begin{array}{l}\text { social interaction anxiety->perceived } \\
\text { task technology fit }\end{array}$ & -0.260 & $3.671^{* * *}$ & Yes \\
\hline
\end{tabular}

Note: ${ }^{* * *} \mathrm{p}<0.001$

\section{Moderation Effect Results}

For a moderator to be significant, 1) main effects as indicated in table 3 should be significant; 2) regression with the moderating variable should be significant; 3 ) the absolute values of the coefficients should be become smaller (Aiken et al., 2013). Table 5 summarizes the results from SEM with the moderator where the coefficient absolute values both get smaller. The absolute values of the coefficients are smaller because the moderator of the perceived IT integration capacity is added to the model and turns out to be effective. The perceived IT integration capacity makes significant impacts on the relationships between work from home stressors and task technology fit $(ß=-0.229, \mathrm{p}<0.01)$, and the moderator has a meaningful impact on the relationship between the perceived social interaction anxiety and task technology fit $(ß=-0.140, \mathrm{p}<0.01)$.

The perceived IT integration capacity makes a significant difference in moderating the negative impacts from work from home stressors and social interaction anxiety.

Table 5. SEM with Moderation Effects of Perceived IT Integration Capacity

\begin{tabular}{|c|l|l|l|l|}
\hline Hypothesis & Relationship & $\begin{array}{l}\text { Beta } \\
\text { coefficient }\end{array}$ & t-value & $\begin{array}{l}\text { Hypothesis } \\
\text { supported }\end{array}$ \\
\hline $\mathrm{H}_{3}(-)$ & work from home stressors & -0.229 & $3.118^{* * *}$ & Yes \\
\hline $\mathrm{H}_{4}(-)$ & $\begin{array}{l}\text { social interaction } \\
\text { anxiety->->task } \\
\text { technology fit }\end{array}$ & -0.140 & $2.671^{* * *}$ & Yes \\
\hline
\end{tabular}

\section{CONCLUSION}

The study shows that participants' social interaction anxiety and work from home stressors negatively influence perceived task technology fit. Specifically, the perceived IT integration capacity alleviates the negative effects of stressors and social interaction anxiety on the perceived task technology fit. There are lots of challenges facing an organization when most employees are working from home such as maintaining corporate culture, mental health of employees, employee productivity, and life-work balance at home etc. Our study has important implications for practitioners. CEOs should be aware of the challenges of work from home and recognize the positive impacts from IT integration capacity for work from home. To avoid negative work stressors and anxiety, CEOs must understand the capacity of the IT integration and their effects. They should have a right IT infrastructure in place and integrate all the IT capability to provide support to their work from home employees.

The present study has a few limitations. First, the data was collected from the subjects who only had two months' work from home experiences, all of them WeChat users, and the sample size is small. Second, our study only found the negative effects of work stressors and anxiety on task technology fit. However, other personal characteristics such as self-esteem and perceived social distance may also have potential impacts on work from home task technology fit. We are not able to include task characteristics in our research. As work from home is such ongoing and dynamic, both companies and their employees face lots of uncertainties from the pandemic crisis such as sudden changes in the government policies, clients canceling orders, and when family members are infected, etc. Thus, future studies are encouraged to include more individual variables and task characteristic features to further examine their effects and IT integration capacity on task technology fit. 
From academic perspective, this research provides another proof that the task-technology fit model (Goodhue \& Thompson, 1995) is truly helpful in analyzing technology-to-performance chain effects.

\section{REFERENCES}

Aiken, M., Wang, J., \& Gu, L. (2013). Task Knowledge and Task-Technology Fit in a Virtual Team. International Journal of Management, 30 (1) 3-12,

Bala, H., Massey, A. \& Montoya, M. (2017). The Effects of Process Orientations on Collaboration Technology Use and Outcomes in Product Development. Journal of Management Information Systems, 34(2), 520-559.

Benitez, J \& Walczuch, R. (2012). Information technology, the organizational capability of proactive corporate environmental strategy and firm performance: a resource-based analysis, European Journal of Information System, 21(6), 664-679.

Bharadwaj, S., Bharadwaj, A., and Bendoly, E. (2007). The performance effects of complementarities between information systems, marketing, manufacturing, and supply chain processes, Information System. Research, 18(4), 437-453.

Braojos, J., Benitez, J., Llorens, J., and Ruiz, L. (2020) Impact of IT integration on the firm's knowledge absorption and desorption. Information \& Management (in press).

Cavanaugh, M.A. Boswell, W.R. Roehling, M.V., and Boudreau, J.W. (2000). An empirical examination of self-reported work stress among U.S. managers, Journal of Applied Psychology, 85, pp. 65-74.

Chen Xiaofang , Ma, Jianqing, Wei, June, and Yang, huiqing (2020). The role of perceived integration in WeChat usages for seeking information and sharing comments: A social capital perspective, Information \& Management (in press).

Ding, Guanqi, Liu, Hefu, Huang, Qian, and Gu, Jibao (2019). Enterprise social networking usage as a moderator of the relationship between work stressors and employee creativity: A multilevel study, Information \& Management, 56,103-165.

Durward, D., Ivo, B., and Leimeister, J M (2020). The Nature of Crowd Work and its Effects on Individuals' Work Perception. Journal of Management Information Systems, 37(1), 66-95

Firth, B.M., Chen, G., Kirkman, B.L., and Kim, K. (2013). Newcomers abroad: expatriate adaptation during early phases of international assignments, Academy of Management Journal, 57(1), 280-300.

Goodhue, D., \& Thompson, R. (1995). Task-technology fit and individual performance. MIS Quarterly 19(2), 213236.

Gu, L \& Wang, J. (2009). A Study of Exploring The “Big Five” And Task Technology Fit In Web-Based Decision Support Systems. Issues in Information Systems. Volume X, No. 2, 211-219.

Guan, Y., Wei Q., and Chen, G. Enterprise social networking usage as a moderator of the relationship between work stressors and employee creativity: A multilevel study. Decision Support Systems, 118 (2019) 58-69

Liu, X., Min, Q., Wu, D, and Liu Z. (2019). How does social network diversity affect users' lurking intention toward social network services? A role perspective. Information \& Management (in press).

Liu, L. Cheung, C. and Lee, M. (2016). An empirical investigation of information sharing behavior on social commerce sites, International Journal of Information Management, 36(5), 686-699. 
Lu, His -Peng \& Yang Yi-Wen. Toward an understanding of the behavioral intention to use a social networking site: An extension of task-technology fit to social-technology fit. Computers in Human Behavior, 34 (2014) 323-332

McCord, B., Rodebaugh, T.L., and Levinson, C.A. (2014). Facebook: social uses and anxiety, Computers in Human Behavior, 34, 23-27.

Parkes, A. (2013). The Effect of Task-Individual-Technology Fit on User Attitude and performance: An Experimental Investigation. Decision Support Systems, 54, 997-1009

Pinjani, P. and Palvia, P. (2013). Trust and knowledge sharing in diverse global virtual teams, Information \& Management, 50 (4), 144-153.

Rai, A. and Tang,X. (2010). Leveraging IT capabilities and competitive process capabilities for the management of interorganizational relationship portfolios, Information System Research, 21(3), 516-542.

Rachman, S., Radomsky, A.S., Shafran,R. (2008). Safety Behavior: A Reconsideration, Behavior Research \& Theory, 46, 163-173.

Shen, X.L, Li, Y.J., Sun,Y., Chen, Z., and Wang F. (2019). Understanding the role of technology attractiveness in promoting social commerce engagement: Moderating effect of personal interest. Information \& Management, 56, 294-305.

Wallace, J.C., Edwards, B.D., Arnold, T. Frazier, M.L, and Finch, D.M. (2009). Work stressors, role-based performance, and the moderating influence of organizational support, Journal of Applied Psychology, 94 (1), 254-262.

Yang, S., Liu,Y., and Wei, J. (2016). Social capital on mobile SNS addiction: a perspective from online and offline channel integrations, Internet Research. 26, 982-1000.

Zhou, T., Lu, Y., and Wang, B. (2010) Integrating TTF and UTAUT to explain mobile banking user adoption. Computers in Human Behavior, 26(4), 760-767.

\section{Appendix}

Task-technology fit (TTF) (Lu and Yang, 2014)

1: In my opinion, my work from home systems' functions are suitable for helping me complete my work or coursework Perceived impacts

2: In my opinion, my work from home systems' functions are enough to help me complete my work or coursework

3. In my opinion, my work from home systems' functions are fit for the requirements of my work or coursework

Social Interaction Anxiety (Liu et al., 2019)

1. I get nervous if I have to interact with someone in authority on zoom meeting.

2. I worry about expressing myself in case I appear awkward on virtual systems.

3. I worry about saying something embarrassing online.

Working from home Stressors (adapted from Ding et al., 2019)

1. The number of projects and or assignments I have.

2. The volume of work that must be accomplished in the allotted time.

3 Time pressures I experience.

4. The amount of responsibility I have. 


\section{Issues in Information Systems}

Volume 21, Issue 4, pp. 18-25, 2020

5. The inability to understand clearly what is expected of me on the job.

6. The lack of job security I have.

IT integration capability (Ding et al., 2019)

1. The work from home systems enable us integrated access and sharing of all order-related data

2. The work from home systems enable us integrated access and sharing of all customer-related data

3. The work from home systems enable us integrated access and sharing of all market-related data

4. To what extent do your IT systems facilitate coordinated activities with external agents 